\title{
Spatio-temporal dynamics of schistosomiasis in Rwanda between 2001 and 2012: impact of the national Neglected Tropical Disease control programme
}

\author{
Elias Nyandwi, ${ }^{1,2}$ Tom Veldkamp, ${ }^{1}$ Frank Badu Osei, ${ }^{1}$ Sherif Amer ${ }^{1}$ \\ ${ }^{1}$ Faculty of Geo-Information Science and Earth Observation, University of Twente, Enschede, \\ The Netherlands; ${ }^{2}$ Geographic Information Systems and Remote Sensing Centre, University of Rwanda, \\ Huye, Rwanda
}

\begin{abstract}
Correspondence: Elias Nyandwi, Faculty of Geo-Information Science and Earth Observation (ITC), University of Twente, P.O. Box 217, 7500 AE, Enschede, the Netherlands.

Tel: +31.0622217023 - Fax: +31.0534874400.

E-mail: nyasept@gmail.com; e.nyandwi@utwente.nl

Contributions: EN, TV, FBO and SA participated in the design of the study and in drafting the manuscript. EN organised and analysed the data, interpreted the results and reviewed the literature under the supervision and substantial contribution of TV, FBO and SA. All authors have been involved in results interpretation and drafting of the manuscript and have read and approved the manuscript before submission.
\end{abstract}

Conflict of interest: the authors declare no potential conflict of interest.

Funding: the work was financially supported by the NICHE/RWA/071 project.

Ethical statement: this study is part of an ongoing research project approved by the Rwanda Biomedical Centre, Division of Malaria and Others Parasitic Disease of Rwanda Biomedical Centre (RBC/M\&OPD). The health records from the Rwandan Health Management Information System (R-HMIS) were provided as aggregated counts without personal information.

Acknowledgments: the authors would like to thank the Dutch Government for financial support through Nuffic Programme under NICHE/RWA/071 project. We are very thankful to Rwanda Biomedical Centre/Malaria and Other Parasitic Disease Division (RBC/M \& OPD) and its staff members (Corine Karema, Noella Umulisa, Irenée Umulisa, Alain Kabayiza, Alphonse Rukundo, Alphonse Mutabazi and Eugene Ruberanziza) for providing health records on schistosomiasis mansoni incidence and additional information related to the disease, particularly in Rwanda.

Key words: Spatiotemporal; Schistosomiasis; Schistosoma mansoni; Health facility service area; Rwanda.

Received for publication: 27 September 2016.

Revision received: 2 December 2016.

Accepted for publication: 4 December 2016.

(C) Copyright E. Nyandwi et al., 2017

Licensee PAGEPress, Italy

Geospatial Health 2017; 12:514

doi:10.4081/gh.2017.514

This article is distributed under the terms of the Creative Commons Attribution Noncommercial License (CC BY-NC 4.0) which permits any noncommercial use, distribution, and reproduction in any medium, provided the original author(s) and source are credited.

\begin{abstract}
Schistosomiasis is recognised as a major public health problem in Rwanda. We aimed to identify the spatio-temporal dynamics of its distribution at a fine-scale spatial resolution and to explore the impact of control programme interventions. Incidence data of Schistosoma mansoni infection at 367 health facilities were obtained for the period 2001-2012. Disease cluster analyses were conducted using spatial scan statistics and geographic information systems. The impact of control interventions was assessed for three distinct sub-periods. Findings demonstrated persisting, emerging and re-emerging clusters of schistosomiasis infection across space and time. The control programme initially caused an abrupt increase in incidence rates during its implementation phase. However, this was followed by declining and disappearing clusters when the programme was fully in place. The findings presented should contribute to a better understanding of the dynamics of schistosomiasis distribution to be used when implementing future control activities, including prevention and elimination efforts.
\end{abstract}

\section{Introduction}

Reliable updates of the number of people currently infected by schistosomiasis worldwide are difficult to come by as they depend on the level of sensitivity of the diagnostic techniques used. Although the figure of 250 million infected victims given by Hotez et al. (2014) is probably an understatement, it is close to figures previously given by the World Health Organization (WHO) and most authors. Mortality is even more difficult to pin down but the figure provided by the Global Burden of Disease (GBD) study in 2010 (Lozano et al., 2012) shows that the disease is primarily chronic. Left untreated, schistosomiasis causes damage to the bladder, kidneys, liver, spleen and also other organs depending on which species of the parasite is involved (van der Werf, 2003).

Schistosomiasis is an important neglected tropical disease (NTD) recognised as a major public health problem (TRAC+, 2008). In Rwanda, intestinal schistosomiasis caused by Schistosoma mansoni is the only form of the disease, so the morbidity seen does not include the urogenital system. Until 2007, the spatial prevalence pattern within Rwanda remained unidentified. In that year, the Rwandan Ministry of Health $(\mathrm{MoH})$ established an NTD control programme, which started with a nation-wide mapping of NTD prevalence based on a cross-sectional survey of randomly sampled primary schools in each of the country's 30 districts (TRAC+, 2008). School survey outcomes were extrapolated to district-level prevalence maps, which were subsequently used to guide a control initiative (Figure 1). The initiative started with 
a three-year project (2008-2010) with several intervention measures targeting the most endemic districts. The nationwide NTD interventions included mass drugs administration (MDA), training of health workers on diagnosis, treatment and transmission control. Health promotion materials were also distributed.

Figure 1 shows the schistosomiasis prevalence in the 2007-08 period, including the implementation of MDA using praziquantel, while Figure 2 illustrates the achievement of the control initiative. We considered three subsequent periods of the control programme, the first of which shows the period before its establishment (up to in 2007), the second, the implementation period that was surprisingly associated with an abrupt increase (2008-2010). However, this increase was most probably attributed to improved diagnosis that was part of the programme implementation. The third period from 2010 onwards depicts the programme when fully operational, which was characterised by a steep decline in the number of incidence, apparently stabilising to a level comparable to the pre-2007 situation. Thus despite the control effort, the number of confirmed cases of schistosomiasis remains high at the national level. Recent studies by Ruberanziza et al. $(2010,2015)$ also identified changes of focal areas with relatively high prevalence. Some of the recently identified areas with high prevalence are located in districts initially classified as being of low endemicity.

Since schistosomiasis can have a highly localised distribution (Gray et al., 2011), a spatio-temporal assessment based on routinely collected incidence data at primary health facilities, can be done using local clustering methods to identify areas with high disease occurrence (Anselin, 1995; Song and Kulldorff, 2003; Bernasco and Elffers, 2010; Quick and Law, 2013). Local clustering methods can be used to identify if cases are geographically concentrated (spatial clusters), tend to be placed closer in time (temporal clus- ters), or are close both in space and time - spatio-temporal clusters (Tango, 2010). Few studies, however, have aimed at the detection of spatio-temporal schistosomiasis at a detailed spatial scale. A notable exception is Gao et al. (2014) who analysed spatio-temporal clustering of schistosomiasis japonica at the village level in Anhui province in China.

The objectives of this study were to explore the spatio-temporal distribution dynamics of schistosomiasis in Rwanda between 2001 and 2012, and to investigate the linkage of this distribution with the NTD control programme interventions. We aimed to analyse these outcomes to assess the impact and effectiveness of the current elimination strategy in Rwanda.

\section{Materials and Methods}

The systematic spatio-temporal variation of Schistosomiasis mansoni incidence rates at health facility service area (HFSA) was detected with Kulldorff's Spatial Scan Statistics (SaTScan v9.4.2) and results were visualised with GIS software ArcGIS, v. 10.4 (ESRI, Redlands, CA, USA).

\section{Study area}

Rwanda, a small, densely populated, landlocked country of $26,338 \mathrm{~km}^{2}$ in the Great Lakes region of central-eastern Africa, is administratively divided into five provinces, 30 districts and 416 sectors (MINALOC, 2005). Administrative sectors together are subdivided into 376 primary HFSA, each of which has one Health Centre with one or more health post or dispensary, which routinely reports to the district health department unit. The methodology
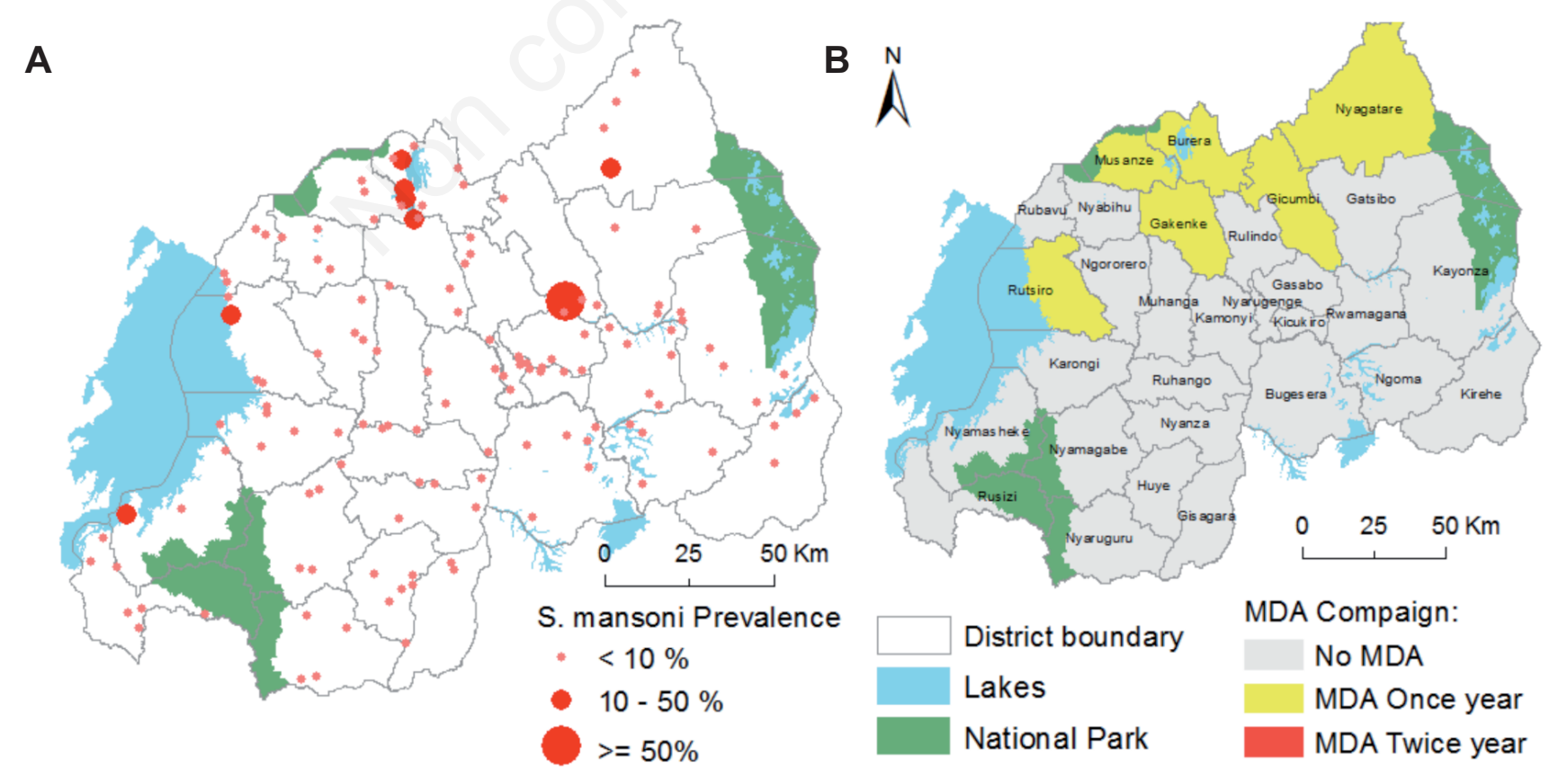

Figure 1. Distribution of schistosomiasis in Rwanda with indication of areas prioritised for control. A) Prevalence map from 2007-08 school-based prevalence survey; B) areas prioritised for mass drugs administration. 
developed for demarcation of the HFSA boundaries is documented in our previous study (Nyandwi et al., unpublished material). Rwanda has a relatively dense and dynamic hydrological network with many lakes and rivers and numerous floodplains and wetlands covering $10 \%$ of the land surface (Nyandwi et al., 2015). The Government of Rwanda considers marshland as an important resource for the intensification of agriculture (mainly rice cultivation), to achieve the goal of food security in the context of Vision 2020 (http://www.minecofin.gov.rw/index.php?id=148), implemented through a five years economic development and poverty reduction strategy.

\section{Data on schistosomiasis infection and population}

Patients suspected to have schistosomiasis are asked and instructed how to collect and submit stool specimen, which were subsequently subjected to testing for eggs of soil transmitted helminths (STH) and Schistosoma mansoni using the Kato-Katz technique (Katz et al., 1972). Trained medical laboratory technicians conducted the sample analysis. Two slides per stool specimen were prepared and read separately. The result recorded per patient was the mean of the reading of the two slides (egg count or number of eggs per gram of stool). The number of confirmed schistosomiasis cases per primary health facility were recorded and first reported in an Excel table and later loaded into the Rwandan Health Management Information System (R-HMIS) every month by each primary health facility using a web-based software platform called DHIS 2 (USAID/Rwanda, 2006). The recorded cases, without personal information, were provided by the Malaria and Other Parasitic Diseases Division of the Rwanda Biomedical Centre (RBC/M\&OPD). The dataset consisted of laboratory confirmed cases from all public and faith-based primary health facilities for the period January 2001 to December 2012.

The disease data were felt to be representative for several reasons, such as: i) health service accessibility - primary health facilities are within walking distance for most people ( $<5 \mathrm{~km}$ distance); ii) affordability - health care for most Rwandans is facilitated by the community-based health insurance (patients pay only $10 \%$ of the total cost of service and medication); iii) encouragement community health workers actively stimulate patients to visit the primary health facility in case of suspected health problems; and iv) medication - there is no traditional medicine used for schistosomiasis in Rwanda, patients with symptoms are treated at the primary health facility.

Demographic data were extracted from the 2002 and 2012 Population and Housing Census published by the National Institute of Statistics of Rwanda (NISR). For the years between, population data were estimated using the average national population growth rate of $2.6 \%$ (NISR and MINECOFIN, 2014). The resulting population data from 2001 to 2012 for each HFSA was prepared as input for the space-time analysis in SaTScan. In addition, the coordinates file was prepared as X, Y of centroids for each HFSA generated in ArcGIS v. 10.4.

\section{Spatial and space-time clustering analysis}

The annual number of confirmed schistosomiasis cases per HFSA were stored in Excel tables. Kulldorff's spatial scan statistic (SaTScan), a widely application in epidemiology (Hanson and Wieczorek, 2002; Read et al., 2011; Yao et al., 2011), was used to identify HFSAs with significantly high incidence rates. Given that we had data of confirmed cases for the period 2001-2012 a retrospective analysis (spatial and space-time) was applied. The analysis was performed using SaTScan 9.4.2 (Kulldorff, 2015).

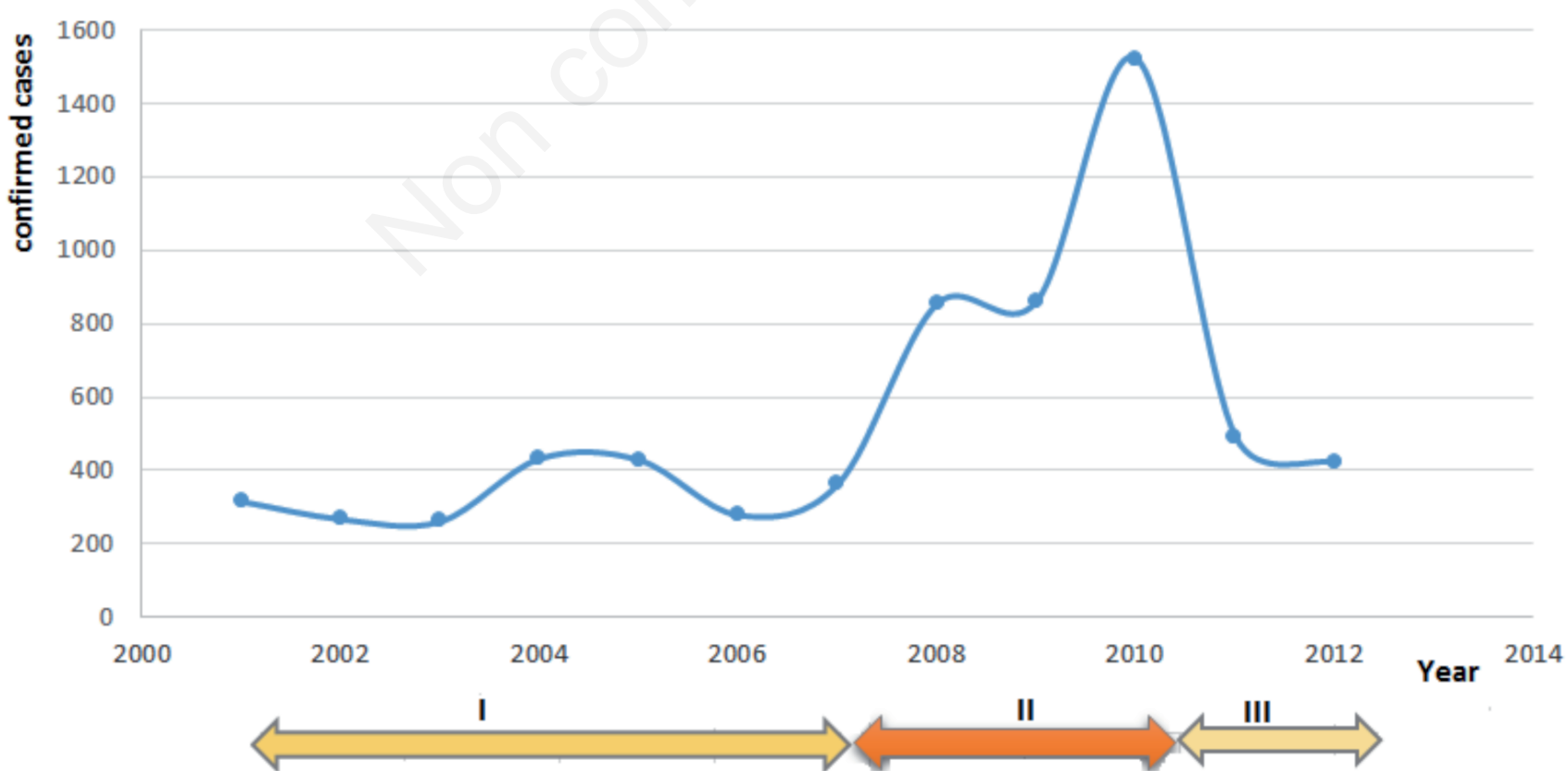

Figure 2. Reported schistosomiasis cases between 2001-2012. The three identified time periods are: I (before the neglected tropical disease control programme), II (during the three years of neglected tropical disease control initiation), and III (the period when the neglected tropical disease programme had become fully functional). 
The advantage of the SaTScan over other local cluster analysis methods is that it calculates a likelihood test statistic, avoids multiple testing and has a variable scan window which prevents preselection bias (Mather et al., 2006). SaTScan determines statistical significance without specifying the number of areas or location of the clusters before calculating the level of significance; all significant clusters must reject the null hypothesis based on their strength (Almeida, et al., 2011; Kulldorff, 2015). Because of this, any rearrangement of cases outside of the scan window will not change the cluster significance level (Song and Kulldorff, 2003). The level of significance is determined through Monte Carlo hypothesis testing, an estimate of the rank of likelihood of the real data based on randomised versions of the same dataset (Kulldorff, 2015). The likelihood ratio is calculated as:

$$
L R(Z)=\frac{L(Z)}{L_{0}}=\left(\frac{c(Z)}{n(Z)}\right)^{c(Z)}\left(\frac{C-c(Z)}{C-n(Z)}\right)^{C-c(Z)}
$$

where $L R(Z)$ represents the likelihood ratio for scan window $Z$ which is calculated as the likelihood of the alternative hypothesis of spatial clustering $(L(Z))$ divided by the likelihood of the null hypothesis of complete spatial randomness $\left(L_{0}\right) . c(Z)$ is the observed number of cases in scan window $Z, n(Z)$ the expected number of cases inside $Z$, and $C$ the total number of cases.

After the likelihood ratio (LLR), a $\mathrm{P}$ value is estimated by comparing the rank of the maximum LLR from the real data set with the highest LLR from the random datasets using Monte Carlo simulation. We set the number of replications to 999 times. Clusters with $\mathrm{P}<0.05$ indicate raised risk. Relative risk (RR) was calculated for each statistically significant cluster (Kulldorff, et al., 1998) by comparing the risk within the cluster in a particular time and area with the risk outside the cluster.

\section{Spatial clustering analysis}

Spatial clusters were detected using SaTScan's circular window that scans the entire study area. The radius of the circle can be varied continuously from zero to a specified maximum spatial window size, corresponding to the maximum percentage of the total population at risk. Since we expected to identify highly localised clusters, we followed the recommendation of Gao et al. (2014) and opted for the maximum window size to contain $10 \%$ of the population at risk. For each window, the observed cases inside and outside the circle were compared to the number of expected cases, as calculated using the Poisson distribution. The window with the maximum likelihood ratio was identified as the most likely (primary) cluster (Kulldorff, 1997). Subsequent likelihood ratios with significance levels of $<0.05$ were considered secondary clusters.

\section{Space-time clustering analysis}

For detection of space-time clusters, the cylindrical approach was used. Here the window was used as described above, while the temporal aspect was expressed as the height of a cylinder with that window as base. The window started with the minimum radius and height at one location and was then moved throughout the study area with a continuously varying radius and height until reaching the upper limit of the radius. The maximum spatial window was set at $10 \%$ of the population at risk, while the height was set at $50 \%$ of the total length of the study period.

\section{Cluster detection within sub-periods of study period}

Figure 2 identifies three sub-periods that coincide with the time before, during and after the implementation of the NTD control programme. Therefore, the methodology described above was first applied to the entire study period and then repeated for each of the three identified sub-periods. The underlying motivation for this was to facilitate the analysis of the impact of the intervention.

\section{Results}

\section{Investigation of spatial schistosomiasis clusters}

Transmission of schistosomiasis was found to be concentrated in 32 spatial clusters as shown in Table 1. The most likely cluster found was Ntaruka HFSA situated in Burera District in the Northern Province. The secondary most likely cluster was seen in Jarama HFSA located in Ngoma District in the Eastern Province. The largest cluster consisted of 18 HFSAs located in Rusizi and Nyamasheke Districts in the Western Province.

\section{Investigation of schistosomiasis clusters}

As shown in Figure 3 and Table 2, sixteen spatiotemporal clusters were identified between 2001 and 2012. The most likely cluster had a high LLR of 2798.3, and the least likely had an LLR of $28.4(\mathrm{P}<0.001)$. This demonstrated that a statistically significant clustering pattern of schistosomiasis incidence existed both in time and space. The most likely cluster was Ntaruka HFSA showing high rates for the six-year period of 2003-2008. A similar persistence in time was observed in cluster 4 (2007-2012) and cluster 10 (2005-2010). Many spatio-temporal clusters existed only for one year (in 2008, 2009 and 2010). If we consider geographical distribution, all 16 spatiotemporal clusters were situated near lakes, main rivers and floodplain wetlands, which all are known for schistosomiasis transmission due to the presence of habitats of the intermediate snail host.

\section{Relation to the national neglected tropical disease con- trol programme}

\section{Clustering in each sub-period}

The results of the spatial scan statistic for each of the three subperiods is visualised in Figure 4. There were 19, 29 and 11 clusters observed in Rwanda for sub-periods I, II, and III, respectively. While the LLR of the primary cluster remained very much higher compared to the LLR value of the secondary likely cluster 2, the geographical location and size of the identified most likely clusters differed for each of the three sub-periods.

During sub-period I (Figure 4A), the most significant schistosomiasis cluster was in the North, corresponding to the Ntaruka HFSA. During sub-period II the primary cluster was in the Southeast, i.e. the Jarame HFSA located in Ngoma district, Eastern Province (Figure 4B). In sub-period III, the most likely cluster, covered very a large area, in the South-West (Figure 4C). In subperiod III all clusters were located in the periphery of the country, with the central parts no longer exhibiting high rates of infection. Cluster number 4 (Kigali City) and 6 (Gisagara District) were, however, exceptions. This meant that hotspots had shifted to peripheral areas, with the most likely cluster in the extreme Southwest and numerous new hotspots in the eastern periphery. 


\section{Spatial and temporal cluster dynamics}

We distinguish three categories of clusters. The first category consisted of persistent clusters, i.e. areas characterised by high rates of schistosomiasis in each of the three sub-periods. There are four such persistent areas (Nkombo Island, Bugarama, NtarukaKinoni and Gikonko) that were seen in the whole study period, and appeared in each sub-period. The second category were emergent clusters, characterised by presence in areas which were originally not highly prevalent but became so after 2007 . The third category consisted of disappearing clusters, areas with high rates of schistosomiasis during sub-period I but not seen during the two later in sub-periods. In these clusters, the rate declined significantly over time.

As can be seen in Figure 1, the prioritised areas target zones with prevalence greater than $10 \%$. The mass MDA was planned at the district level using prevalence classes as follow: no MDA for district with $<10 \%$ prevalence; once a year for school children and women of child-bearing age where prevalence was $<30 \%$ and twice a year all where the prevalence was greater $>30 \%$.

\section{Discussion}

The focal spatial distribution of schistosomiasis mansoni in Rwanda was confirmed by the spatial scan statistics space-time analysis used in this study. As illustrated in Figure 2, the annual number of confirmed schistosomiasis cases in the period 20012012 exhibited considerable variation over time. During the first seven years, the period before the NTD control programme, we observe slightly varying medium-level numbers of infections that

Table 1. Spatial clusters of schistosomiasis (2001-2012).

\begin{tabular}{|c|c|c|c|c|c|c|}
\hline Cluster identified & HFSAs involved & Name(s) of HFSAs with clusters & LLR & $\mathbf{R R}$ & Obs & Exp \\
\hline 1 & 1 & Ntaruka/Kinoni & 2828 & 197 & 668 & 4 \\
\hline 2 & 1 & Jarama & 807 & 26 & 356 & 14 \\
\hline 3 & 2 & Cyanika, Kinyababa & 597 & 10 & 438 & 47 \\
\hline 4 & 18 & $\begin{array}{l}\text { ushenge, Bugarama, Gihundwe, Gisakura, Kibogora, } \\
\text { esha, Mibilizi, Nyamasheke, Mushaka, Muyange, Mwezi, } \\
\text { Nkungu,Nyabitimbo, Mukoma, Rangiro, Ruharambuga, Rusizi }\end{array}$ & 576 & 4 & 1156 & 374 \\
\hline 5 & 1 & Bugarama & 517 & 9 & 403 & 47 \\
\hline 6 & 5 & Cyabayaga, Karama, Mimuli, Rukomo, Rurenge & 443 & 7 & 444 & 73 \\
\hline 7 & 1 & Nkombo & 432 & 20 & 212 & 11 \\
\hline 8 & 4 & Cyondo, Mimuli, Muhambo, Rukomo & 354 & 7 & 327 & 48 \\
\hline 9 & 1 & Kibogora & 254 & 11 & 176 & 17 \\
\hline 10 & 1 & Rwesero & 200 & 27 & 86 & 3 \\
\hline 11 & 1 & Rusoro & 188 & 10 & 132 & 13 \\
\hline 12 & 4 & Cyabingo, Murandi, Nyundo, Rwaza & 181 & 5 & 236 & 51 \\
\hline 13 & 1 & Cyimbili & 148 & 10 & 109 & 12 \\
\hline 14 & 1 & Gikonko & 130 & 10 & 96 & 10 \\
\hline 15 & 1 & Mwendo & 121 & 14 & 72 & 5 \\
\hline 16 & 1 & Bisate & 85 & 6 & 87 & 14 \\
\hline 17 & 1 & Rugarama & 80 & 4 & 117 & 28 \\
\hline 18 & 2 & Murara, Byahi/Gacuba & 79 & 3 & 168 & 53 \\
\hline 19 & 1 & Nzige & 74 & 6 & 84 & 15 \\
\hline 20 & 2 & Ntaruka/Nasho, Gituku & 64 & 7 & 62 & 9 \\
\hline 21 & 3 & Gasiza, Kinoni-Gahunga, Mucaca & 61 & 3 & 143 & 48 \\
\hline 22 & 1 & Humure & 54 & 7 & 53 & 8 \\
\hline 23 & 4 & Gisakura, Mukoma, Muyange, Nyamasheke & 49 & 3 & 141 & 54 \\
\hline 24 & 2 & Nyagahita-Nyagatare, Rurenge & 45 & 4 & 83 & 24 \\
\hline 25 & 1 & Busanza & 37 & 3 & 101 & 38 \\
\hline 26 & & Mashesha & 31 & 4 & 47 & 11 \\
\hline 27 & 1 & Rusizi & 19 & 3 & 61 & 25 \\
\hline 28 & 4 & Mukono, Bushara, Bwisige, Cyondo & 18 & 2 & 77 & 35 \\
\hline 29 & 1 & Nyamyumba & 15 & 4 & 25 & 6 \\
\hline 30 & 1 & Nyacyonga & 13 & 3 & 36 & 14 \\
\hline 31 & 1 & Gatare-Mugonero & 12 & 4 & 21 & 6 \\
\hline 32 & 1 & Kigufi & 9 & 2 & 41 & 19 \\
\hline
\end{tabular}

HFSA, health facility service area; LLR, log likelihood ratio; RR, relative risk; Obs, observed number of cases in the cluster; Exp, expected number of cases in the cluster. All clusters had statistical significance levels P $<0.01$. 


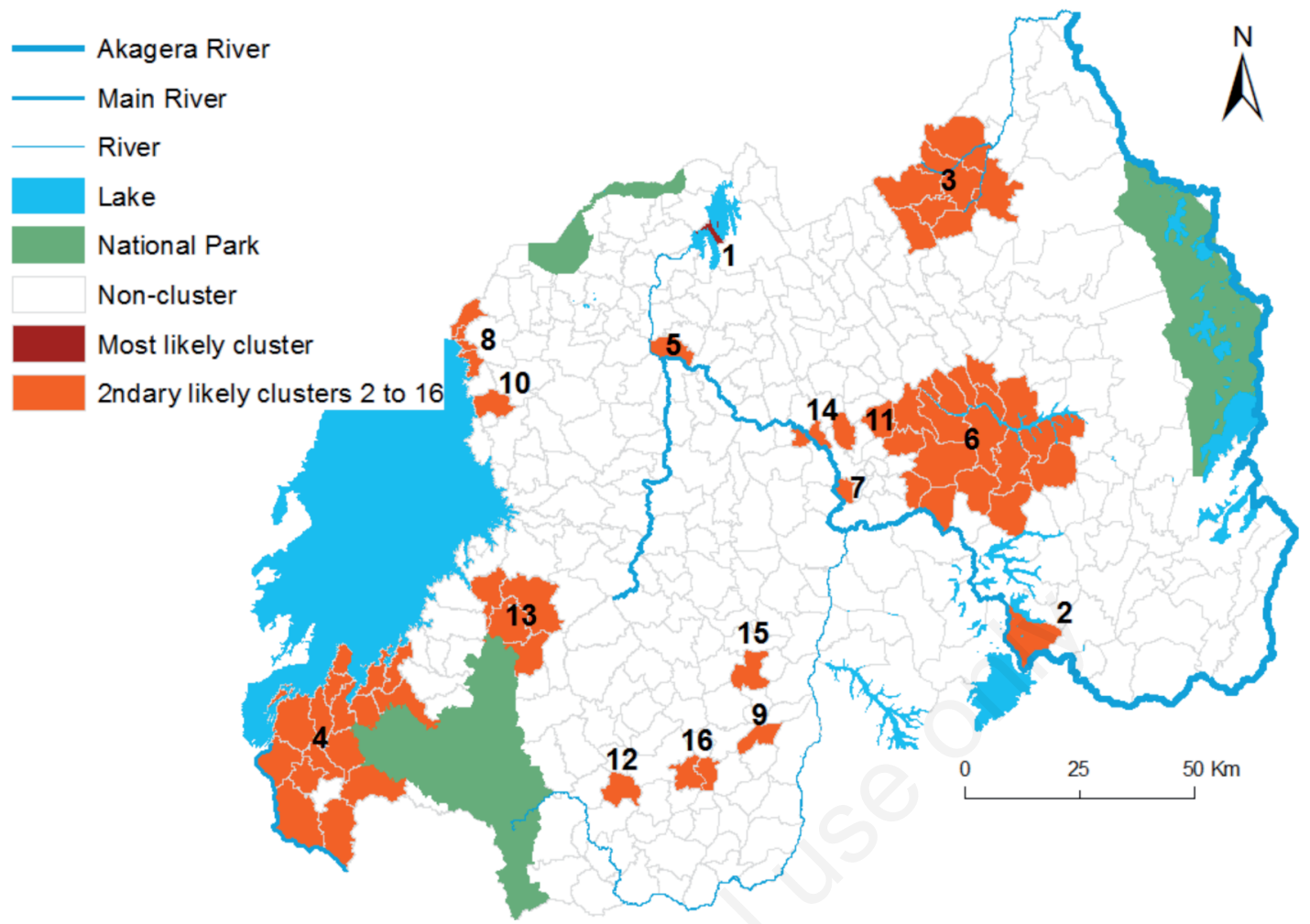

Figure 3. Spatiotemporal schistosomiasis clusters in the period 2001-2012.

Table 2. Spatio-temporal schistosomiasis clusters in order of log likelihood ratio.

\begin{tabular}{|c|c|c|c|c|c|c|c|}
\hline Cluster identified & HFSAs involved & Timeframe & Name(s) of HFSAs with clusters & LLR & $\mathbf{R R}$ & Obs & Exp \\
\hline 1 & 1 & $2003-2008$ & Ntaruka & 2798 & 348 & 582 & 2 \\
\hline 2 & 1 & 2010 & Jarama & 1631 & 283 & 353 & 1 \\
\hline 3 & 9 & $2008-2010$ & $\begin{array}{l}\text { Cyabayaga, Cyondo, Karama, Muhambo, } \\
\text { Mimuli, Nyarurema, Rukomo, Rurenge, Tabagwe }\end{array}$ & 763 & 14 & 451 & 34 \\
\hline 4 & 18 & 2007-2012 & $\begin{array}{l}\text { Bugarama, Bushenge, Gihundwe, Gisakura, } \\
\text { Kibogora, Mashesha, Mukoma, Mibilizi, Mushaka, } \\
\text { Muyange, Mwezi, Nkombo, Nkungu, Nyabitimbo, } \\
\text { Nyamasheke, Rangiro, Ruharambuga, Rusizi }\end{array}$ & 639 & 5 & 869 & 202 \\
\hline 5 & 1 & 2010 & Rusoro & 428 & 102 & 118 & 1 \\
\hline 6 & 18 & 2008-2010 & $\begin{array}{l}\text { Busanza, Gikomero, Gishali, Giti, } \\
\text { Humure, Kayanga, Kinyinya, Masaka, Muhura, } \\
\text { Murambi-Musha-Gahengeri, Muyumbu, Nyagasambu, } \\
\text { Nzige, Rubungo, Ruhunda, Rwesero, Rwimitereri, Tanda }\end{array}$ & 2798 & 348 & 582 & 2 \\
\hline 7 & 1 & 2010-2012 & Mwendo & 1631 & 283 & 353 & 1 \\
\hline 8 & 4 & 2010 & Byahi-Gacuba II, Gisenyi, Kigufi, Murara & 763 & 14 & 451 & 34 \\
\hline 9 & 1 & 2009-2011 & Gikonko & 639 & 5 & 869 & 202 \\
\hline 10 & 1 & 2005-2010 & Cyimbili & 428 & 102 & 118 & 1 \\
\hline 11 & 1 & 2009 & Nyacyonga & 336 & 5 & 438 & 95 \\
\hline 12 & 1 & 2010 & Nyamyumba & 205 & 48 & 71 & 1 \\
\hline 13 & 4 & 2009 & Gisovu, Mugonero, Mukungu-Bisesero, Nyarwungo & 198 & 15 & 111 & 7 \\
\hline 14 & 3 & 2008 & Jali, Kabuga-Kamonyi, Rutonde & 159 & 25 & 70 & 3 \\
\hline 15 & 1 & 2008 & Nyamure & 156 & 15 & 88 & 6 \\
\hline 16 & 2 & 2008 & Mbazi and Sovu & 87 & 30 & 36 & 1 \\
\hline
\end{tabular}

HFSA, health facility service area; LLR, log likelihood ratio; RR, relative risk; Obs, observed number of cases in the cluster; Exp, expected number of cases in the cluster. All clusters had statistical significance levels $\mathrm{P}<0.01$. 
increased sharply during the first three years of control implementation. At first glance, this may come as a surprice, but the explanation is surely a reflection of improved diagnostic coverage. From 2010 onwards, we see a steep decrease in annual incidence, stabilising at the pre-intervention period, which shows the impact of the NTD intervention programme (as the diagnostic coverage remains the same). Taking the annual population growth of $2.6 \%$ into account, we can conclude that incidence rates have been dynamic during the study period. Some HFSA were persistently classified as schistosomiasis cluster-related with different levels of significance. Over time, new focal areas emerged, while others disappeared. Overall, 67 HFSA units out of a total of 367 were identified as areas with increased transmission of the disease. Persistent and emergent clusters amounted to 53 HFSA units, while 14 such units became non-endemic towards the end of the study period.
The observed spatio-temporal changes in high-rate schistosomiasis clusters were associated both with changes in environmental risk factors and impacts of the various interventions measures initiated by the NTD programme. In the following, we discuss in more detail the association between these clusters and the interventions. Furthermore, the observed spatio-temporal dynamics may be explained by analogy from the literature. We structure this discussion by presenting possible relations for persistent clusters, emergent clusters, and disappearing clusters.

Starting at the first three years of the NTD control program, resources for schistosomiasis control (awareness raising, diagnostic equipment, medication, training of health personnel) increased tremendously (Ruxin and Negin, 2012). In three years, nearly $100 \%$ of the population at high risk was covered by at least two MDAs within the priority districts (Sabin Vaccine Institute, 2011).
A

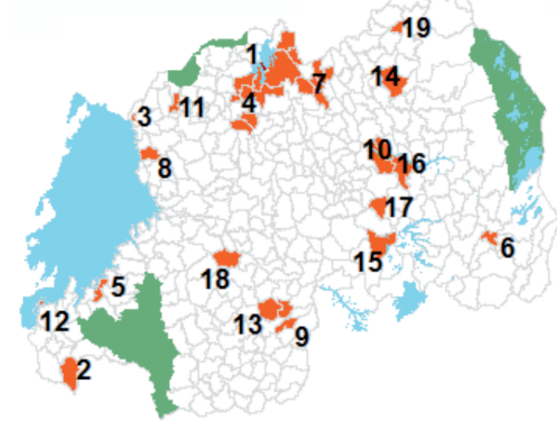

B

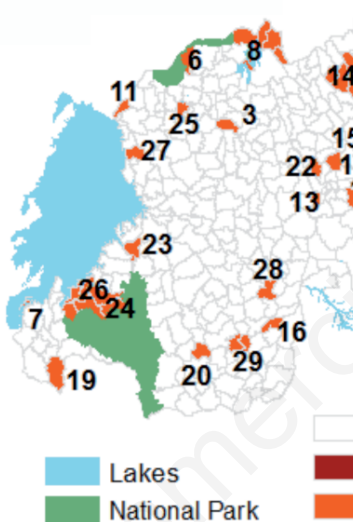

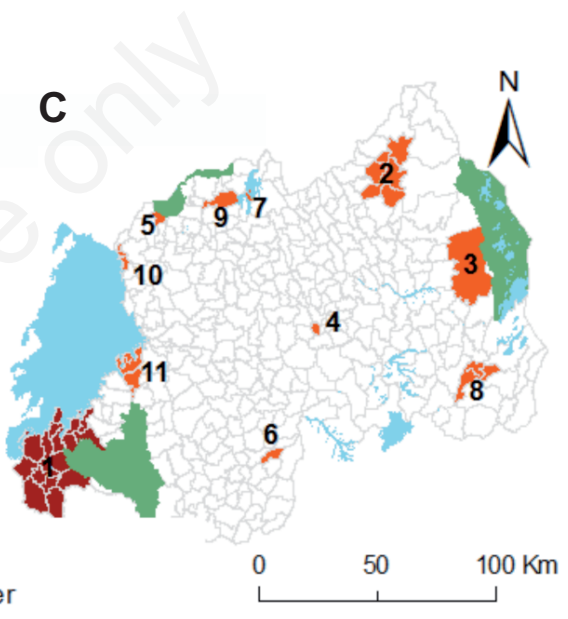

Non-cluster

Most likely cluster

2ndary likely cluster 2- 19/29/11

Figure 4. Spatio-temporal schistosomiasis clusters for the three sub-periods. A) Sub-period I (before the neglected tropical disease control programme, 2001-2007); B), sub-period II (during the first neglected tropical disease control intervention, 2008-2010); and C) sub-period III (with the neglected tropical disease control programme in place, 2011-2012).

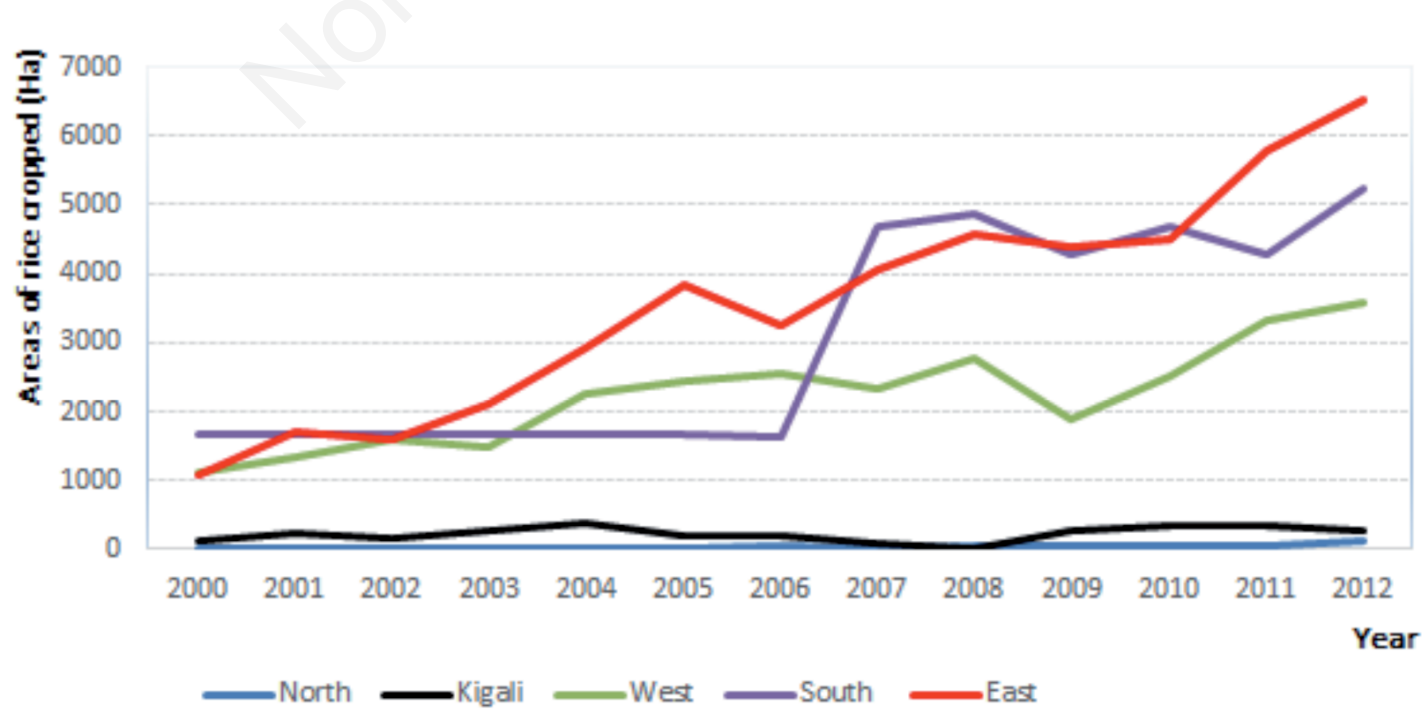

Figure 5. Evolution of rice cultivation areas per province in the period 2000-2012. 
The treatments were accompanied by the distribution of informational and educational materials. At the end of the project, 18,825 health staff were trained to identify symptoms and treatment of intestinal schistosomiasis (Ruxin and Negin, 2012). Increased knowledge of, and means for diagnosis and treatment, probably explains the abrupt increase of confirmed cases during the subperiod II of the program implementation and the general strong decrease of confirmed cases since 2011. Our spatio-temporal analysis demonstrates that most of the schistosomiasis clusters disappeared, or that their significance declined over time. In traditional hotspots, e.g. Ntaruka-Kinoni HFSA in Burera District, rates have declined consistently. Indeed, this area changed from the most important cluster during sub-period I into a secondary cluster in the following two sub-period. Over the course of three years, the selected areas (Figure 1) were covered by repeated MDA campaigns, guided by the district prevalence map of the nationwide prevalence mapping survey. The approaches initiated by the NTD control programme were also complemented by the great positive impact of improved socio-economic conditions (such as increased number of school attendances, access to improved water for domestic use, proper sanitation, wearing shoes, etc.) (Leuchowius, 2014; MINECOFIN, 2015; United Nations, 2000).

Although the mapping exercise was generally of great help in guiding the NTD control initiatives, it did not capture all highprevalence locations. The most probable reason for this was that spatial resolution of the district-level baseline map could have been better. The district-based approach was too aggregated, and therefore some high-rate transmission areas were not detected. For example, Nkombo Island and neighbouring areas are located in districts classified as low-endemic, while Ruberanziza et al. (2015) identified this area as one of the most important foci in Rwanda. However, this area becomes the most important cluster in sub-period III. Since the districts Rusizi and Nyamasheke were falsely considered among the least endemic districts with prevalence rates of 0.7 and $4.5 \%$, respectively (TRAC,+ 2008 ), they did not benefit from control measures during the first three years of the interventions (Figure 1).

Despite, the substantial impact of the well-managed NTD intervention programme, our analysis revealed that the schistosomiasis rates remain high and that there are also new emerging clus-

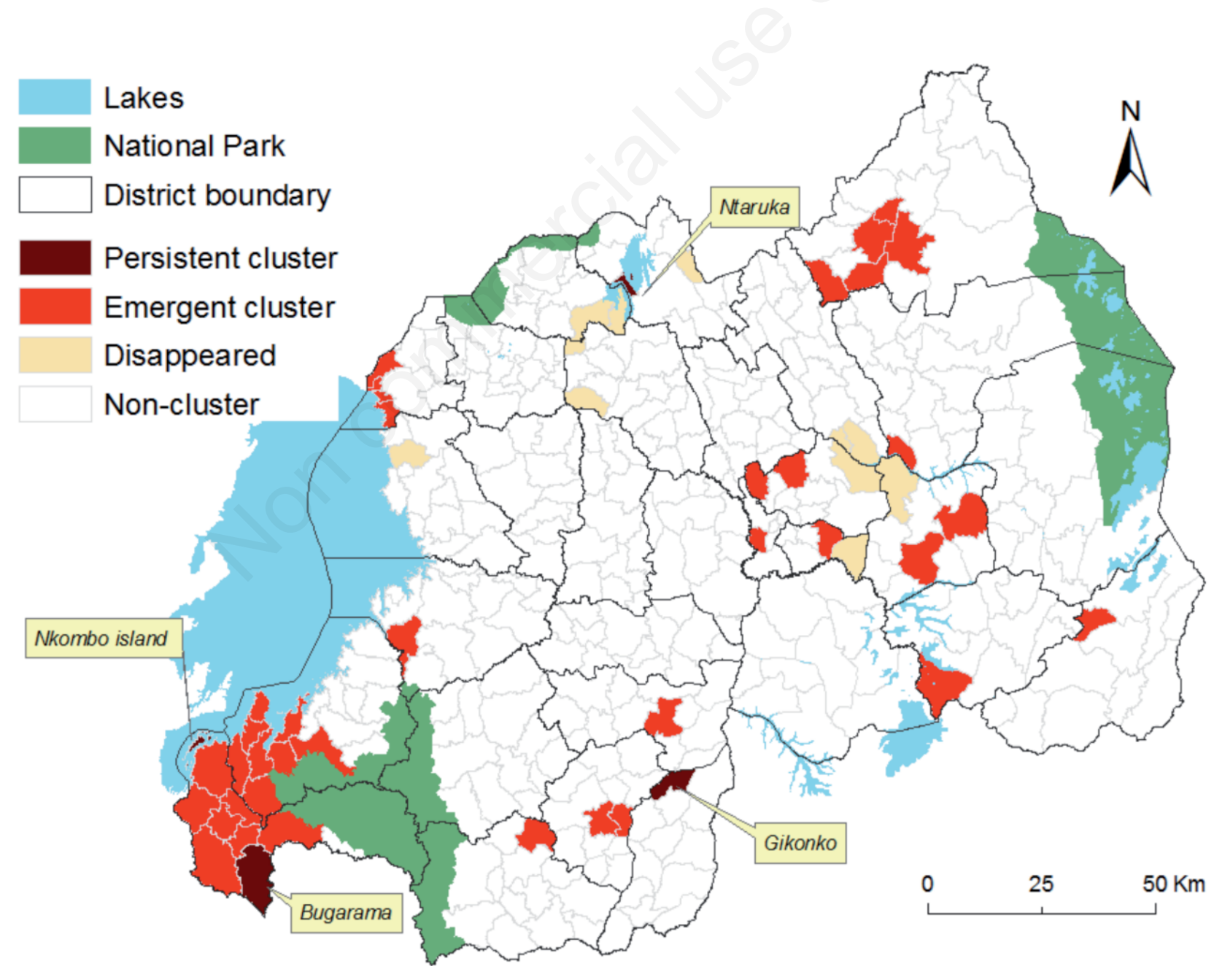

Figure 6. Clusters of high rate schistosomiasis mansoni transmission. Persistent clusters (dark red colour), emerging clusters appearing since 2008 (red colour), clusters that disappeared after control measures had been implemented (sand colour), and non-endemic areas (white). 
ters. Thus, the eradication of the disease is difficult since the transmission factors are still there. The persistent and emergent clusters may be associated with various and changing risk factors as discussed by Steinmann et al. (2006) in a systematic review of dam projects referring to other African countries that are also endemic for schistosomiasis. In Rwanda, the most important risk factors might be related to the extended and new irrigated areas as a result of the agricultural transformation in Rwanda (Malesu et al., 2010). Furthermore, conversion of wetlands for rice cultivation increased from 4000 ha to 13000 ha between 2000 and 210 (Nabahungu and Visser, 2013). Consequently, two of four persistent clusters (Bugarama and Gikonko HFSAs) are both located in areas with the oldest (since the 1980's) and also the largest rice cultivation schemes (Republic of Rwanda, 2010). According to unpublished statistics from Ministry of Agriculture, Rusizi District hosted 20\% of the total rice crops in Rwanda by 2012 and Bugarama District counts more than 6000 of about 17,000 households engaged in rice cultivation. Furthermore, rice cultivation in Rwanda involves the most vulnerable community groups, women and children; more than $45 \%$ of rice farming workers are women (Nkurikiye, 2016). The number of schistosomiasis infections may double or triple for a relatively small number of peoples in temporal shelters/villages of workers concentrated around such water development projects. Adjacent to most wetlands there are relatively flat areas that are easily settled but which lack hygienic conditions, such as tap water and sewage systems. The expansion of irrigated rice cultivation (Figure 5) may explain the expanding clusters in the Eastern Province, as illustrated throughout by Figures 4 and 6 . The Eastern Province totalled $41.5 \%$ of rice cultivation areas in Rwanda by 2012. The expansion of rice cultivation in the Eastern Province took place specifically within Nyagatare District, where rice cropping in the wetlands along Muvumba River increased from 180 to 1350 ha between 2000 and 2012. Also, the Eastern Province, a relatively semi-arid region of the country, a lot of dams have been constructed, and hillside irrigation projects initiated (Malesu et al., 2010; MINAGRI, 2012).

Other persistent clusters (Ntaruka-Kinoni and Nkombo HFSAs) are situated in close proximity of Kivu Lake and the adjacent lakes of Burera and Ruhondo. Most of the inhabitants in these areas are in permanent contact with the lakes when fetching water for domestic use, swimming, and fishing. This finding is in line with other studies highlighting the link between schistosomiasis and water contact (Tukahebwa et al., 2013; Mazigo et al., 2014). Likewise, most of the emerging endemic areas are in proximity to water bodies and man-made agricultural schemes, which supports the intermediate snail host and transmission.

Although the spatially structured data recorded at primary health facilities inform us about the distribution of disease transmission, the people tested constitute just the portion representing the seriously infected persons; the total number of infections is surely much greater. We advocate more actively monitoring for all newly emerging clusters using existing routinely collected data, to guide new intervention programmes. Disease-conscious planning of land use in the future could also help to prevent further increase of the disease.

Although the level of aggregation of the data investigated is relatively small (at the HFSA level), they do not represent the exact geographical location of the infected patients for most HFSAs, as unoccupied areas are not excluded (i.e., protected areas). Thus, the coordinates linked to the HFSA centroid used may not reflect the reality needed/tracked by the spatial scan win- dow applied. However, earlier comparative studies by Torabi and Rosychuk (2011) and Rashidi et al. (2015) show only minor differences between circular and flexible scan statistic methods in cluster analysis.

\section{Conclusions}

The analysis presented here has demonstrated that the presence of schistosomiasis in Rwanda varies across space and time. The impact of the NTD national control programme was clearly reflected by localised clusters, which were either persistent, emerging or disappearing over time. The intervention initiative pushed hotpots of schistosomiasis transmission to the periphery but was not able to eradicate the disease. Persistent clusters with high schistosomiasis rates still occur, while emerging clusters show a linkage with new, large-scale agricultural schemes involving irrigation and rice cropping. The results generated should be highly valuable for a spatially structured evaluation of risk factors associated with schistosomiasis and provide vital information for decision-makers and health planners. The methodology presented and outcomes generated contribute to a better understanding of the dynamics of schistosomiasis and are recommended for future prevention, control and elimination interventions.

\section{References}

Almeida ACL, Duarte AR, Duczmal LH, Oliveira FLP, Takahashi RHC, 2011. Data-driven inference for the spatial scan statistic. Intl J Health Geogr 10:47.

Anselin L, 1995. The local indicators of spatial association - LISA. Geogr Anal 27:93-115.

Bernasco W, Elffers H, 2010. Statistical analysis of spatial crime data. In: R.A. Piquero. D. Weisburd (eds.) Handbook of quantitative criminology. Springer, New York, NY, USA, pp. 699724.

Gao F-h, Abe EM, Li S-Z, Zhang L-J, He J-C, Zhang S-Q, Wang T-P, Zhou X-N, Gao J, 2014. Fine scale. Spatial-temporal cluster analysis for the infection risk of Schistosomiasis japonica using space-time scan statistics. Parasite Vectors 7:578.

Gray DJ, Ross AG, Li Y-S, McManus DP, 2011. Diagnosis and management of schistosomiasis. Brit Med J 342:2651.

Hanson CE, Wieczorek WF, 2002. Alcohol mortality: a comparison of spatial clustering methods. Soc Sci Med 55:791-802.

Hotez PJ, Alvarado M, Basáñez M-G, Bolliger I, Bourne R, Boussinesq M, Brooker SJ, Brown AS, Buckle G, Budke CM, Carabin H, Coffeng LE, Fèvre EM, Fürst T, Halasa YA, Jasrasaria R, Johns NE, Keiser J, King CH, Lozano R, Murdoch ME, O'Hanlon S, Pion SD, Pullan RL, Ramaiah KD, Roberts T, Shepard DS, Smith JL, Stolk WA, Undurraga EA, Utzinger J, Wang M, Murray CJ, Naghavi, M, 2014. The global burden of disease study 2010: interpretation and implications for the neglected tropical diseases. PLoS Neglect Trop Dis 8:e2865.

Katz N, Chaves A, Pellegrino J, 1972. A simple device for quantitative stool thick-smear technique in Schistosomiasis mansoni. Rev Inst Med Trop São Paulo 14:397-400

Kulldorff M, 1997. A spatial scan statistic. Commun Stats-Theory Methods 26:1481-96. 
Kulldorff M, 2015. Software for the spatial and space-time scan statistics. SaTScan V9.4.2. Available from: www.satscan.org

Kulldorff M, Athas WF, Feurer EJ, Miller BA, Key CR, 1998. Evaluating cluster alarms: a space-time scan statistic and brain cancer in Los Alamos, New Mexico. Am J Public Health 88:1377-80.

Leuchowius K, 2014. Report on the health care sector and business opportunities in Rwanda. Available from: http://www.swecare.se/Portals/swecare/Documents/Report-on-the-HealthCare-Sector-and-Business-Opportunities-in-RwandaSep2014-vers2.pdf

Lozano R, Naghavi M, Foreman K, Lim S, Shibuya K, Aboyans V, Abraham J, Adair T, Aggarwal R, Ahn SY, Alvarado M, Anderson HR, Anderson LM, Andrews KG, Atkinson C, Baddour LM, Barker-Collo S, Bartels DH, Bell ML, Benjamin EJ, Bennett D, Bhalla K, Bikbov B, Bin Abdulhak A, Birbeck G, Blyth F, Bolliger I, Boufous S, Bucello C, Burch M, Burney P, Carapetis J, Chen H, Chou D, Chugh SS, Coffeng LE, Colan $\mathrm{SD}$, Colquhoun S, Colson KE, Condon J, Connor MD, Cooper LT, Corriere M, Cortinovis M, de Vaccaro KC, Couser W, Cowie BC, Criqui MH, Cross M, Dabhadkar KC, Dahodwala N, De Leo D, Degenhardt L, Delossantos A, Denenberg J, Des Jarlais DC, Dharmaratne SD, Dorsey ER, Driscoll T, Duber H, Ebel B, Erwin PJ, Espindola P, Ezzati M, Feigin V, Flaxman AD, Forouzanfar MH, Fowkes FG, Franklin R, Fransen M, Freeman MK, Gabriel SE, Gakidou E, Gaspari F, Gillum RF, Gonzalez-Medina D, Halasa YA, Haring D, Harrison JE, Havmoeller R, Hay RJ, Hoen B, Hotez PJ, Hoy D, Jacobsen KH, James SL, Jasrasaria R, Jayaraman S, Johns N, Karthikeyan G, Kassebaum N, Keren A, Khoo JP, Knowlton LM, Kobusingye O, Koranteng A, Krishnamurthi R, Lipnick M, Lipshultz SE, Ohno SL, Mabweijano J, MacIntyre MF, Mallinger L, March L, Marks GB, Marks R, Matsumori A, Matzopoulos R, Mayosi BM, McAnulty JH, McDermott MM, McGrath J, Mensah GA, Merriman TR, Michaud C, Miller M, Miller TR, Mock C, Mocumbi AO, Mokdad AA, Moran A, Mulholland K, Nair MN, Naldi L, Narayan KM, Nasseri K, Norman P, O'Donnell M, Omer SB, Ortblad K, Osborne R, Ozgediz D, Pahari B, Pandian JD, Rivero AP, Padilla RP, Perez-Ruiz F, Perico N, Phillips D, Pierce K, Pope CA 3rd, Porrini E, Pourmalek F, Raju M, Ranganathan D, Rehm JT, Rein DB, Remuzzi G, Rivara FP, Roberts T, De León FR, Rosenfeld LC, Rushton L, Sacco RL, Salomon JA, Sampson U, Sanman E, Schwebel DC, Segui-Gomez M, Shepard DS, Singh D, Singleton J, Sliwa K, Smith E, Steer A, Taylor JA, Thomas B, Tleyjeh IM, Towbin JA, Truelsen T, Undurraga EA, Venketasubramanian N, Vijayakumar L, Vos T, Wagner GR, Wang M, Wang W, Watt K, Weinstock MA, Weintraub R, Wilkinson JD, Woolf AD, Wulf S, Yeh PH, Yip P, Zabetian A, Zheng ZJ, Lopez AD, Murray CJ, AlMazroa MA, Memish ZA, 2012. Global and regional mortality from 235 causes of death for 20 age groups in 1990 and 2010: a systematic analysis for the Global Burden of Disease Study 2010. Lancet 380:2095128.

Malesu MM, Oduor AR, Chrogony K, Nyolei D, Gachene CKK, Biamah EK, O’Neil M, Ilyama M, Mogoi J, 2010. Rwanda irrigation master plan. Ebony Company Limited and World Agroforestry Centre (ICRAF), Nairobi, Kenya.

Mather FJ, Chen VW, Morgan LH, Correa CN, Shaffer JG, Srivastav SK, Rice JC, Blount G, Swalm CM, Wu X, Scribner RA, 2006. Hierarchical modeling and other spatial analyses in prostate cancer incidence data. Am J Prev Med 30(Suppl.2): 88-100.

Mazigo HD, Dunne DW, Wilson S, Kinung'hi SM, de Moira AP, Jones FM, Morona D, Nuwaha F, 2014. Co-infection with Schistosoma mansoni and human immunodeficiency virus-1 (HIV-1) among residents of fishing villages of north-western Tanzania. Parasite Vectors 7:1-9.

MINAGRI, 2012. Small dams safety guidelines. Ministry of Agriculture and Animal Resources, Kigali, Rwanda.

MINALOC, 2005. Organic law no 29/2005 of 31/12/2005 determining the administrative entities of the Republic of Rwanda. Official Gazette of the Republic Rwanda, Kigali, Rwanda.

MINECOFIN, 2015. Demographic and health survey [DHS] 2014/2015. Key findings. Ministry of Finance and Economic Planning, Kigali, Rwanda.

Nabahungu NL, Visser SM, 2013. Farmers' knowledge and perception of agricultural wetland management in Rwanda. Land Degrad Dev 24:363-74.

NISR, MINECOFIN, 2014. Rwanda fourth population and housing census 2012. Thematic report on population size, structure and distribution. National Institute of Statistics of Rwanda, Kigali, Rwanda.

Nkurikiye JB, 2016. Rice cooperatives in Rwanda: a perspective on resource use. Imp J Interdisc Res 2:101-14.

Nyandwi E, Veldkamp TA, Amer S, 2015. Regional climate sensitivity of wetland environments in Rwanda: the need for a location-specific approach. Reg Environ Change 16:1635-47

Quick M, Law J, 2013. Exploring hotspots of drug offences in Toronto: a comparison of four local spatial cluster detention methods. Can J Criminol Crimin Jus 55:215-38.

Rashidi P, Wang T, Skidmore A, Vrieling A, Darvishzadeh R, Toxopeus B, Ngene S, Omondi P, 2015. Spatial and spatiotemporal clustering methods for detecting elephant poaching hotspots. Ecol Model 297:180-6.

Read S, Bath P, Willett P, Maheswaran R, 2011. Measuring the spatial accuracy of the spatial scan statistic. Spatial Spatiotemporal Epidemiol 2:69-78.

Republic of Rwanda, 2010. Enabling self sufficiency and competitiveness of Rwanda rice. Issues and policy options. Ministry of Agriculture and Animal Resources, Republic of Rwanda, Kigali, Rwanda. Available from http:/www.minagri.gov.rw/ fileadmin/user_upload/documents/agridocs/Rwa_RicePolicyR eport.pdf

Ruberanziza E, Kabera M, Ortu G, Kanobana K, Mupfasoni D, Ruxin J, Fenwick A, Nyatanyi T, Karema C, Munyaneza T, Katja P, 2015. Nkombo Island: the most important Schistosomiasis mansoni focus in Rwanda. Am J Life Sci 3:2731.

Ruberanziza E, Mupfasoni D, Karibushi B, Kabera M, Karema C, Nyatanyi T, Ruzindana E, Gatabazi JB, Mukabayire O, Fenwick A, Ruxin J, 2010. A recent update of Schistosomiasis mansoni endemicity around lake Rweru. Rwanda Med J/Rev Med Rwand 68:5-9.

Ruxin J, Negin J, 2012. Removing the neglect from neglected tropical diseases: the Rwandan experience 2008-2010. Glob Public Health 7:812-22.

Sabin Vaccine Institute, 2011. Working toward sustainable, country-led programs the Burundi and Rwanda. NTD control programs year three annual report May 2009-May 2010. Sabin Vaccine Institute, Washington, DC, USA.

Song C, Kulldorff M, 2003. Power evaluation of disease clustering 
tests. Int J Health Geogr 2:9.

Steinmann P, Keiser J, Bos R, Tanner M, Utzinger J, 2006. Schistosomiasis and water resources development: systematic review, meta-analysis, and estimates of people at risk. Lancet Infect Dis 6:411-25.

Tango T, 2010. Statistical methods for disease clustering. Springer, Amsterdam, the Netherlands.

Torabi M, Rosychuk RJ, 2011. An examination of five spatial disease clustering methodologies for the identification of childhood cancer clusters in Alberta, Canada. Spat Spatiotemporal Epidemiol 2:321-30.

TRAC,+ 2008 . Report of the National school prevalence survey on soil-transmitted helminthiasis and schistosomiasis in school aged children. Rwanda Ministry of Health, Kigali, Rwanda.

Tukahebwa EM, Magnussen P, Madsen H, Kabatereine NB, Nuwaha F, Wilson S, Vennervald BJ, 2013. A very high infec- tion intensity of Schistosoma mansoni in a Ugandan Lake Victoria fishing community is required for association with highly prevalent organ related morbidity. PLoS Neglect Trop Dis 7:e2268.

United Nations, 2000. Millenium summit of the United Nations. Available from: http://www.un.org/en/development/devagen$\mathrm{da} /$ millennium.shtml

USAID/Rwanda, 2006. Rwanda HMIS assessment report. Rwanda Ministry of Health, Kigali, Rwanda.

van der Werf MJ, 2003. Schistosomiasis morbidity and management of cases in Africa. University Medical Center, Rotterdam, the Netherlands.

Yao Z, Tang J, Zhan F, 2011. Detection of arbitrarily-shaped clusters using a neighbor-expanding approach: a case study on murine typhus in South Texas. Int J Health Geogr 10:1-17. 